\title{
Study of component composition and particle size distribution of dust emissions to solve the problems of environmental quality management
}

\author{
S. Yu. Zagorodnov, A. A. Kokoulina \& E. V. Popova \\ Federal Budget Scientific Institution, Federal Scientific Center for \\ Medical and Preventive Health Risk Management Technologies, Russia
}

\begin{abstract}
This paper describes the stages of research of dust emissions from industrial enterprises and the results obtained. An analysis of dust emissions was undertaken to determine their component composition, $\mathrm{PM}_{10}$ and $\mathrm{PM}_{2.5}$ fine particles proportion and morphological characteristics. The data received were considered in a population exposure evaluation.

Keywords: dust emissions, fine particles, component composition, $P M_{10}, P M_{2.5}$, exposure assessment.
\end{abstract}

\section{Introduction}

Dust emissions from industrial plants contain a large amount of different chemical components, comprising ash, soot, smoke, sulfates, nitrates, metal oxides and other solid components. As a result of enterprises' industrial processes and combustion of all fuel types, dust emissions are generated. Depending on emission compositions, they may be highly toxic or almost harmless. The size of dust particles emitted by enterprises is defined by the process environment and the composition of raw materials being utilized. Numerous studies have shown harmful effects of dust particles on public health. Particles that have fractions less than 10 microns $\left(\mathrm{PM}_{10}\right)$ and less than 2.5 microns $\left(\mathrm{PM}_{2.5}\right)$ are particularly significant. This is due to the fact that these particles have a very small size, which allows them to penetrate not only into the upper respiratory tract, but also into the lower divisions of human respiratory 
organs. The effect of fine dust particles on human health is due to both short and long-term exposure, and thus they can cause respiratory and cardiovascular diseases [1-3]. The second important point in the study of industrial dust emissions is a lack of relevant information on their dispersion and component composition. Development of the production base, an introduction of up-to-date technological processes and use of new chemical components require the adjustment and supplement of existing characteristics of dust emissions set out in the 1980s [4]. Atmospheric air quality management in terms of dust emissions requires the presence of correct data on their dispersion and component composition. Currently in the Russian Federation there is not enough information of this type. Particle size distribution and component composition of dust emissions of enterprises in machine building, mining, petrochemical and ironand-steel industries were examined by specialists of the Federal budget scientific institution "Federal Scientific Center for Medical and Preventive Health Risk Management Technologies" in the course of research in 2011-2013.

\section{Purpose}

The purpose of the study was to examine particle size distribution and component composition of industrial dust emissions followed by an assessment of population exposure in a zone affected by emissions.

\section{Subjects}

Enterprises of ferrous and non-ferrous metallurgy, machine building, mining and petrochemical industries were the subjects of the study.

\section{Methods of study}

The main sources of dust were determined for each type of production, which were described in terms of the following points:

- description of process/equipment, which results in dust formation and release.

- information on dust particle size distribution defining shares of $\mathrm{PM}_{2.5}$ and $\mathrm{PM}_{10}$.

- information on dust component composition defining a share of each chemical agent.

- particle morphology.

The following instruments and equipment that allowed us to preserve dust fractional composition were used in the research:

- Microtrac S3500 laser particle analyzer (covering particle size range from $20 \mathrm{~nm}$ to 2000 microns) was used to determine particle size distribution of dust emissions.

- scanning electronic microscope with high resolution (magnification range from 5 to 300,000 times) with S3400N "HITACHI" X-ray fluorescence 
attachment used for dust microscopy to determine particle shape and component composition of dust emission.

- X-ray phase analysis of samples with XRD-700 "Shimadzu" X-ray diffractometer was carried out to determine chemical composition.

\section{Research results}

It was found that practically all emissions of studied industries contain fine particles that are hazardous to human health, including toxic impurities, mainly heavy metals. Thus, particulate emissions of ferrous and non-ferrous metallurgy contain 8-84\% $\mathrm{PM}_{10}, 4-78 \% \mathrm{PM}_{2.5}$, emissions of engineering enterprises contain 4-40\% $\mathrm{PM}_{10}, 5-20 \% \mathrm{PM}_{2.5}$, mining emissions contain 15-50\% $\mathrm{PM}_{10}, 2-25 \%$ $\mathrm{PM}_{2.5}$. Histograms of particle size distribution of dust emissions from studied enterprises in ferrous and non-ferrous metallurgy, machine building, mining and petrochemical industries are presented in Figure 1.

Median particle sizes of different industries range from 4 to 800 microns. In some cases, nano-scale particles (with a diameter less than 0.01 micrometers) were identified in emissions. The greater part of the emissions component composition (over 50\%) consists of toxic impurities and metal oxides: iron, aluminium, lead, titanium, copper, manganese, zinc and chromium. Figure 2 shows spectrograms of studied emission components from a process equipment operation.

Depending on process environment, particles were studied morphologically, and have irregular, fragmented, angular, rounded shapes. Figure 3 shows examples of dust particles emitted into the atmosphere by industrial enterprises.

Calculations of dust emission dispersion from large industrial plant sources were carried out to establish zones of influence of fine dust particle emission and compare them with zones of emission influence regardless of particle size distribution. Optimal ratios of particle sedimentation rate were selected for dust after identification of particle size distribution, which was used to predict exposure. Based on calculation findings, the maximum concentration of dust particles less likely to disperse at a border of normal areas was 0.30 , the threshold level value of acute exposure (manganese and its compounds). Maximum concentration of $\mathrm{PM}_{10}$ was 0.97 , the threshold level value of acute exposure. In the example considered, a zone of influence of fine particles $\left(\mathrm{PM}_{10}\right)$ exceeds the dimensions of the zone of influence of dust particles with only their chemical composition taken into account. Dispersion calculations showed that metering fine particles in industrial enterprise emissions greatly increases accuracy of the results. Availability of up-to-date data on component composition and particle size distribution of dust emissions will allow industrial companies to prioritize sources of dust emissions and select dust and gas pollution control equipment with greater accuracy. Data of the study were used by enterprises to develop environmental protection measures and the implementation of technical solutions to reduce dust exposure in the population. 


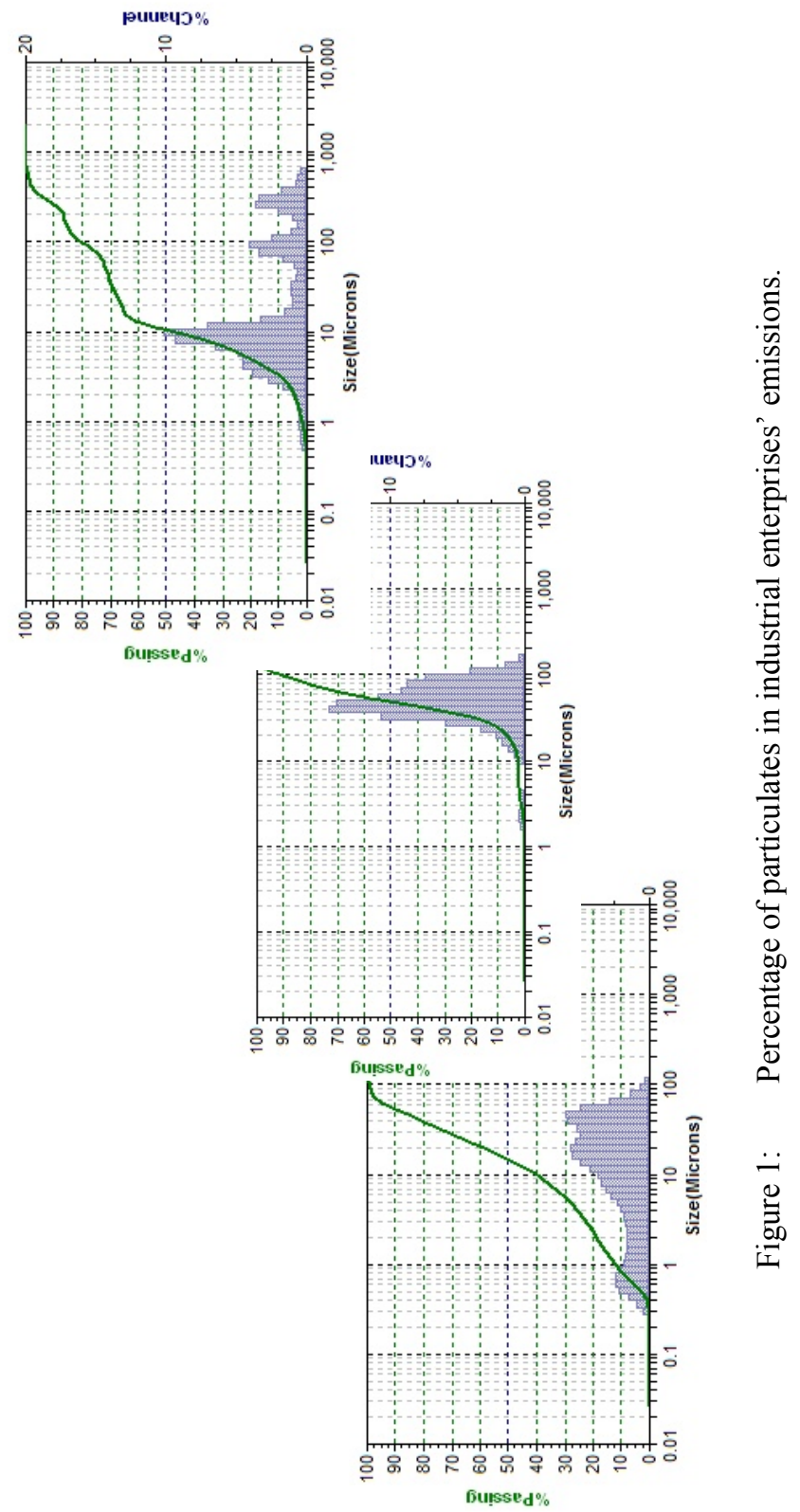




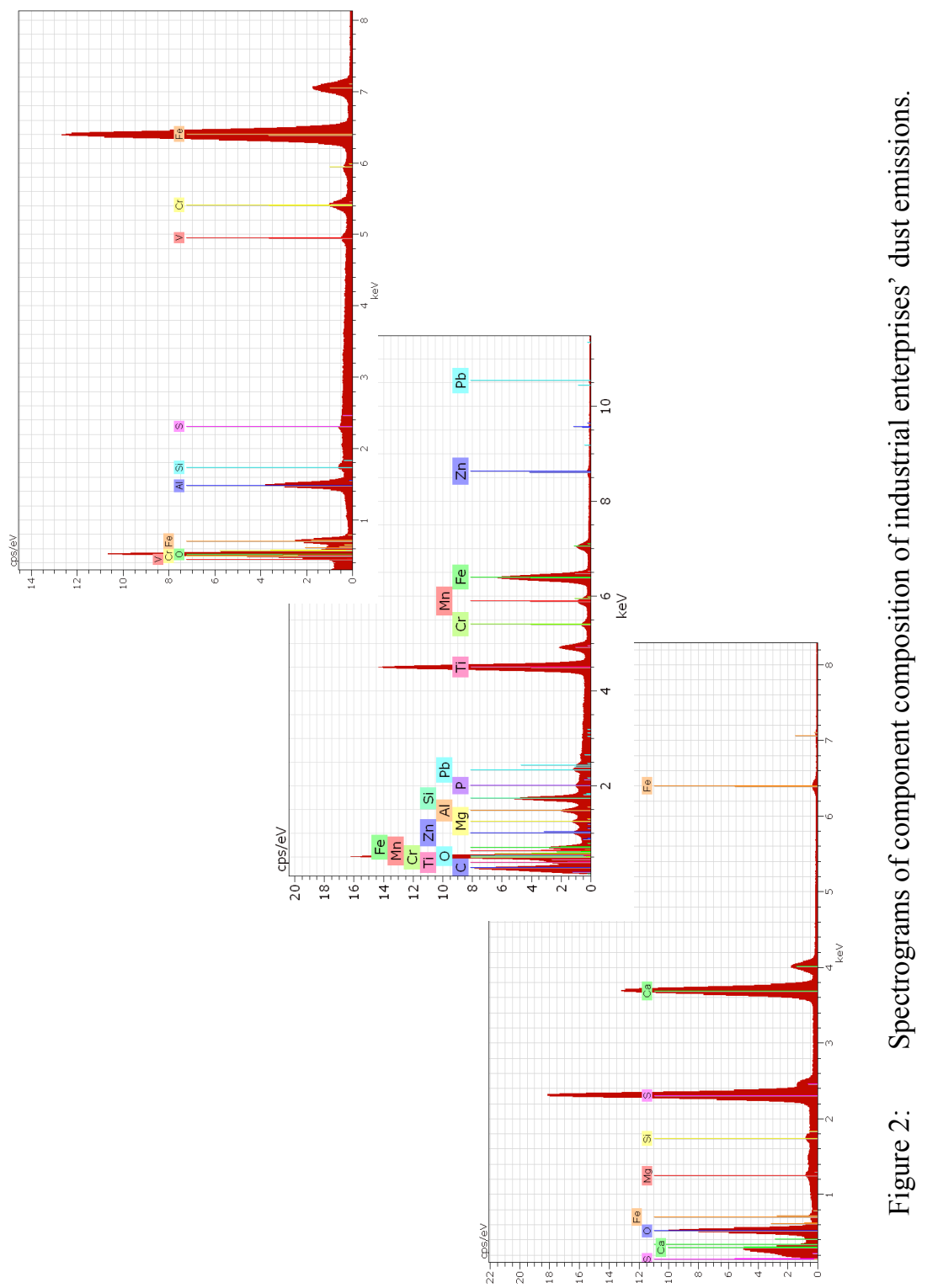



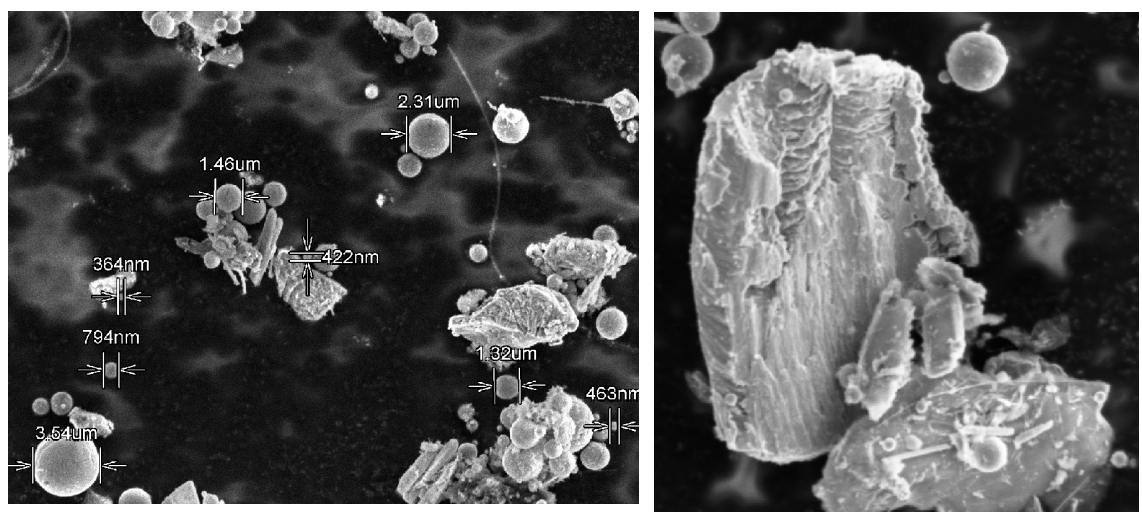

Figure 3: Dust particles emitted into the atmosphere by industrial enterprises.

\section{Summary}

- An absence of up-to-date information on fine particle emissions casts doubt on existing approaches to determine the exposure to people living under the emission influence.

- Studies of dust particles allowed us to determine a component composition of emissions, which in most cases does not meet a classification used by enterprises in emissions' regulation.

- The results of these studies indicate a presence of large amount of fine particles in dust emissions $\left(\mathrm{PM}_{10}\right.$ more than $70 \%, \mathrm{PM}_{2.5}$ more than 50\%).

- An area of atmospheric air pollution zone with due consideration of dusts particle size distribution is larger than an area without due consideration of particle fractionation.

- Metering of particle size distribution reveals real concentrations of fine particles being formed in population residential areas.

- The obtained results of dispersion calculations confirm a relevance of dust emissions studies for assessing the impact on human health.

- An existence of real concentrations of dust emissions including fine particles determines a course of necessary measures and the effect expected.

\section{References}

[1] Jimoda, L.A. (2012). Effects of Particulate Matter on Human Health, the Ecosystem, Climate and Materials: a Review. Facta Universitatis. Series: Working and living Environmental Protection, Vol. 9, № 1, pp. 27-44, 2012.

[2] Cormier, S., Lomnicki S., Backes W., Dellinger B. (2006). Origin and Health Impacts of Emissions of Toxic By-Products and Fine Particles from 
Combustion and Thermal Treatment of Hazardous Wastes and Materials. Environ Health Perspect. pp. 810-817, 2006.

[3] Revich B.A. Environmentally Dependent Changes in Population Health in Russia, Proceedings of International Conference. Humanity and environment. Moscow: MGU - C, 2004.

[4] Skryabina L. Ya. Atlas of Industrial Dusts. Part 1. Fly Ash of Thermal Power Plants. Moscow: Tsintihimneftemash; 1980. Part 2. Dusts of Enterprises of Metallurgy, Engineering and Construction Industries. Moscow: Tsintihimneftemash, 1981. Part 3. Dusts of Enterprises of Chemical and Food Industries. Moscow: Tsintihimneftemash, 1982.

[5] May I.V., Zagorodnov S.Yu., Maks A.A. Fractional and Component Composition of Dust in Working Area of Machine Building Enterprise, Occupational Medicine and Industrial Ecology. № 12, pp. 12-16, 2012. 